\title{
Grass-root level experience on COVID-19 management in the Field Practice Area of NIHS, Kalutara, Sri Lanka
}

\author{
Vidura Jayasinghe", Mahesh Karunatilake, Rasanthi Jayasundera, Nilanthi Suraweera, Tamara \\ Kalubowila, Ruwan Ferdinando
}

National Institute of Health Sciences, Kalutara, Sri Lanka

"Correspondence: vidura.jayasinghe@yahoo.com

iDhttp://orcid.org/0000-0001-6669-7507

DOI:https://doi.org/10.4038/jccpsl.v26i5.8368

Received on 6 May 2020

Accepted on 5 June 2020

\section{Summary}

The COVID-19 pandemic has become the foremost public health concern in this millennium (1). Sri Lanka too is in a challenging position with regards to the disease control process (2). Since the first local case identified on 11 March 2020, the disease has rapidly spread to almost all areas of the country (3). The administrative district of Kalutara has been considered as a high-risk area throughout, within which one cluster was identified in the Field Practice Area (FPA) of National Institute of Health Sciences (NIHS), Kalutara. The NIHS FPA consists of two Medical Officer of Health (MOH) areas, namely Kalutara and Beruwala (4). These two areas provide healthcare services for a total population of 330,203.

\section{Public health response and its impact \\ Case detection at NIHS Field Practice Area}

The process of case finding among the permanent residents of NIHS FPA can be divided into three phases. In the initial phase, the first case was identified on 16 March 2020. The patient had been working in a private hospital in Colombo and did not have any contacts for whom the exposure could be traced in the NIHS FPA. From this patient, the number of confirmed cases increased considerably.
One cluster was identified in Beruwala $\mathrm{MOH}$ Area consisting of 22 cases and from this cluster, 219 suspected people were sent to the Punani Quarantine Centre. The second phase of case finding was observed among the people who were quarantined at Punani and a total of 30 cases were identified among them. The third phase commenced from 24 April 2020 onwards up to 29 April, during which five cases were identified among Navy soldiers from Welisara Navy Base. Figure 1 shows the distribution of 57 cases identified up to 29 April 2020. 


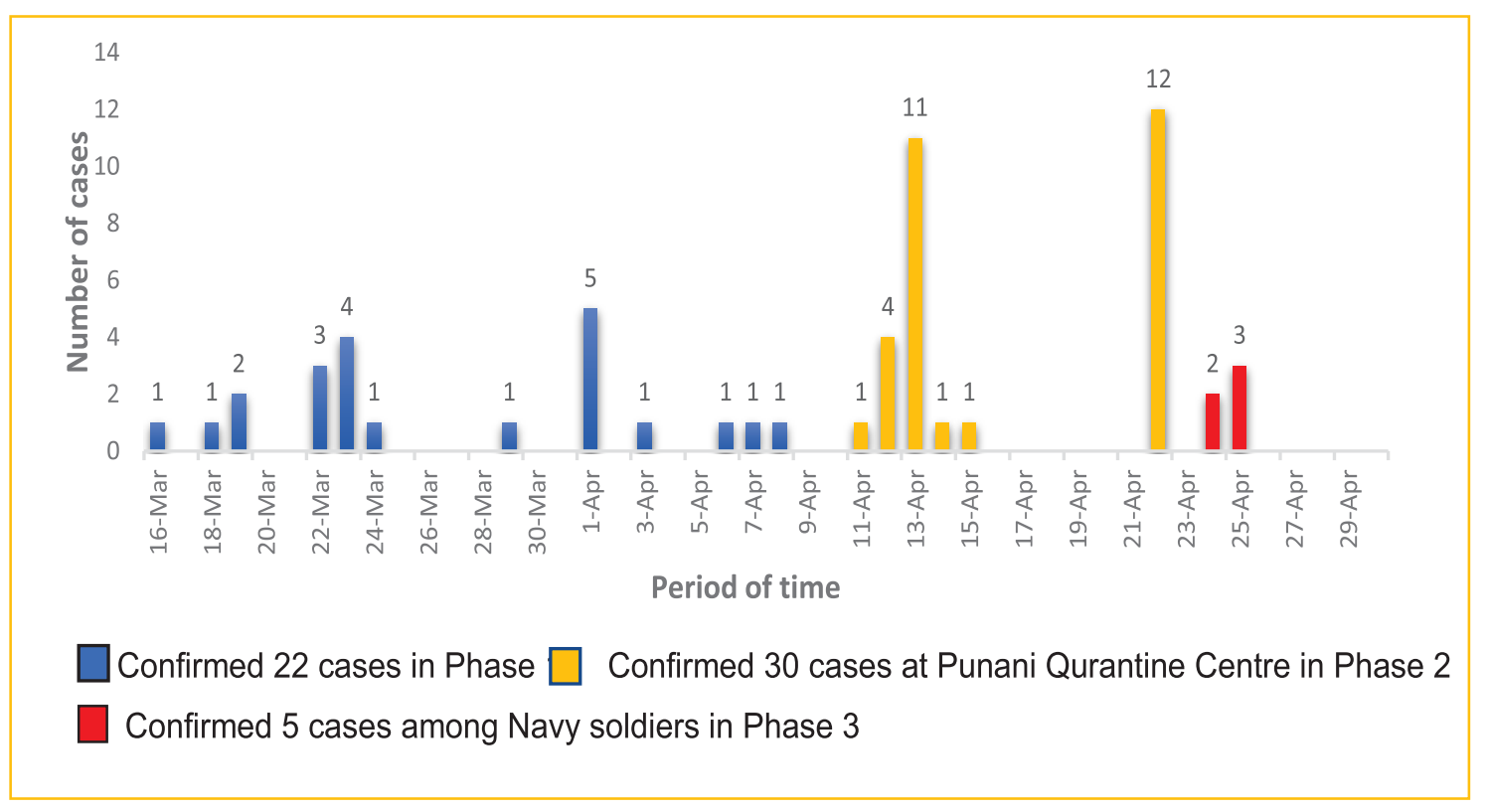

Figure 1: Distribution of confirmed cases from NIHS Field Practice Area (16 March-29 April)

Source: Epidemiological data at Regional Epidemiology Office, NIHS, Kalutara

\section{Contact tracing and quarantine of susceptible individuals}

A thorough contact tracing was conducted by the local public health team and the history related to the sources and contacts was explored for each identified case (5). Five patients had travel histories from several counties such as Italy, Dubai and Indonesia, while four people were engaged in jobs related to the tourism industry. Subsequently, all 'probable' exposed cases were home-quarantined and the identified places were disinfected. In addition, based on the epidemiological criteria (6), many individuals were subjected to Polymerase Chain Reaction (PCR) testing in the community as well.

\section{Declaration of total lockdown at Beruwal}

On 29 March 2020, a case was detected at Beruwala $\mathrm{MOH}$ Area within the above cluster. The patient was a tourist driver by profession and had a history of visiting the Bandaranaike International Airport. However, his history revealed that he had developed symptoms a few days before and had since then visited several places and engaged in a number of activities in the area. Furthermore, the patient had not sought medical advice initially but had self-treated himself at home. During this time period, he had been exposed to a number of people in five GramaNiladhari (GN) Divisions, namely Pannila, Akkaragoda, Ambepitiya, Karandagoda and China Fort. Fourteen close contacts of this person were subjected to PCR testing and four were identified as positive for COVID-19. There have been more than 15,000 people living in the $5 \mathrm{GN}$ divisions and all susceptible people were requested to strictly adhere to quarantine instructions given by the healthcare workers (7). However, it was observed that houses were clustered together in a limited area and that the number residing within a household was high. Furthermore, behaviours of the dwellers were observed to be unsatisfactory as many people had not adhered to the instructions given to maintain adequate social distancing (8). In this background, a possibility that COVID-19 may spread rapidly was anticipated, thus a request was made to declare a total lockdown of the area via the District Secretary of Kalutara on 1 April 2020. At the same time, 219 firstand second-line contacts were identified and sent to Punani Quarantine Centre as an immediate action in controlling the spread of the disease on 1 April 2020. All five GN divisions were declared as complete lockdown areas and strict rules and regulations were implemented from 14 April 2020 onwards. 


\section{Continuation of services in the area}

One of the main requirements was to provide comprehensive health services during this time. However, service provision in lockdown areas was deemed challenging as healthcare providers too were at risk of getting infected with COVID-19 (9). In addition, more health and non-health needs were raised as people were unable to fulfil them in the usual way due to the many restrictions imposed. Therefore, special healthcare provision was initiated in the area whilst taking sufficient precautions to protect healthcare workers.

A special medical clinic was started within the lockdown area with assistance of the medical staff from Beruwala Hospital. It was conducted daily to provide basic out-patient department (OPD) services for people. Furthermore, clinic books of patients suffering from non- communicable diseases (NCD) were obtained and sent to the respective clinics at government hospitals. Patients who obtained the services from private pharmacies were also facilitated to obtain their medicine. The public health inspectors (PHI) involved in drug distribution and medical officer-NCD (MO-NCD) coordinated the process. Apart from this, four patients who needed dialysis and three patients who needed oncology follow-up were identified and their treatment was arranged without any interruption through Base Hospital Homagama and Apeksha Hospital.

Maternal care was continued throughout this period and all pregnant mothers were contacted over the phone. Antenatal clinics were conducted on an appointment basis and the required referrals were arranged. Within the lockdown area, weekly antenatal clinics were continued by the medical officers of $\mathrm{MOH}$ Beruwala. Furthermore, 15 pregnant mothers in the lockdown area were subjected to PCR testing but none of them were positive for COVID-19. On the other hand, nonmedical commodities such as food, water, gas, etc. were continuously provided with the assistance of respective authorities and the process was thoroughly supervised by the PHI.

\section{Intersectoral collaboration}

It is obvious that the challenges which came up during this period could not be resolved by the health sector alone. Thus, multiple stakeholder involvement was greatly required to ensure successful disease containment in the area (10). The tri-forces and police participated not only in implementation of law and order but also in helping healthcare workers to trace contacts, quarantine people and disinfect exposed areas. Furthermore, they were involved in distribution of essential goods within the lockdown area, which was facilitated by the PHIs.

Drug distribution was arranged partly via the postal department, while private pharmacies also engaged in door-to-door delivery. Electricity, water and telecommunication facilities were provided without any interruption by the relevant authorities for the people in the area. In addition, field level government workers such as GN and Samurdhi officer worked around the clock to ensure social welfare and provided services to the required as recommended by departmental regulations. The media provided enormous backing to disseminate information related to activities conducted in the area. Media reports related to activities in the area were telecasted regularly via mass media which enhanced public awareness and acceptance toward COVID-19 management activities.

\section{Public involvement}

Initially, it was not that easy to convince the public the importance of action taken to control the disease. The difficulties encountered in initiating and maintaining positive behavioural changes of people within a short period of time was apparent. It was even observed that maintaining social distancing was not well-practised despite the declaration of curfew and other preventive measures. Public acceptance was very low during the initial phase as they displayed resistance to quarantine instructions and diseases control measures. It was more problematic to identify contacts especially within the cluster in Pannila. A special meeting was conducted with the participation of religious leaders, members of the business community, community leaders and local 
politicians. They agreed to give their fullest support for the healthcare workers. Religious leaders were instrumental in identifying the contacts as they were well aware of the social inter-relationships within the area. Furthermore, they facilitated the conduct of community screening in the mosque at China Fort. The business community helped by providing daily facilities to the community via the PHI (Figure 1).

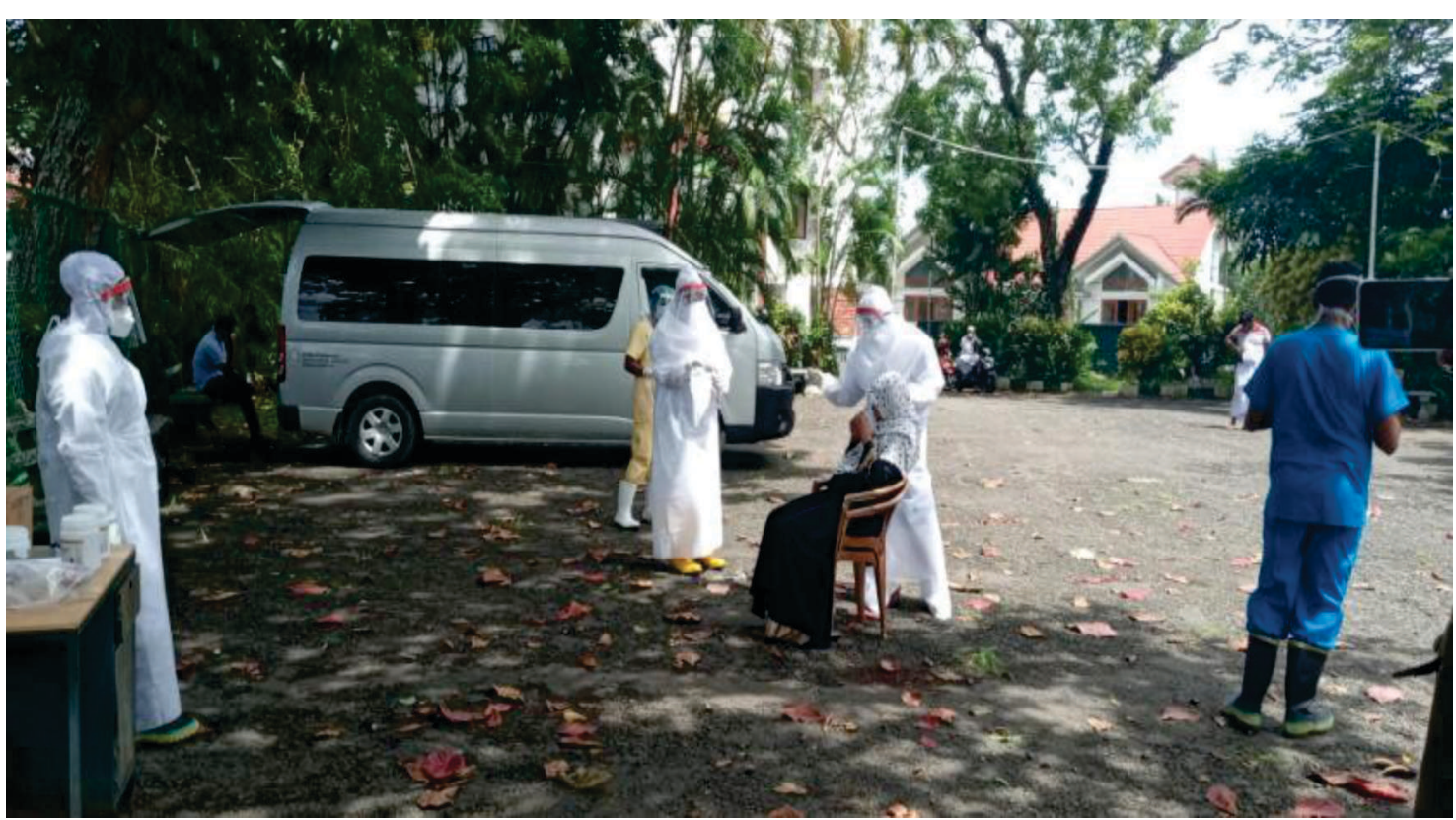

Figure 1: Obtaining a sample for PCR testing at NIHS Field Practice Area

\section{Achievements}

There have been 57 COVID-19 cases identified and 214 subjected to PCR testing up to 29 April 2020. The summary of main indicators related to disease control at NIHS FPA is shown in Table 1.

Table 1: Summary of the main indicators in COVID-19 management at NIHS Field Practice Area up to 29 April 2020

\begin{tabular}{|l|r|}
\hline \multicolumn{1}{|c|}{ Main indicators } & No. \\
\hline Cases identified in the NIHS Field Practice Area & 57 \\
Kalutara MOH area & 6 \\
Beruwala MOH area & 51 \\
\hline Cases cured in NIHS area & 12 \\
Kalutara MOH area & 4 \\
Beruwala MOH area & 8 \\
\hline Persons subjected to home quarantine & 1459 \\
Cases identified among home quarantined persons & 10 \\
\hline People sent to Punani Quarantine Centre & 219 \\
Cases identified at Punani Quarantine Centre & 30 \\
\hline Patients subjected to PCR & 214 \\
Cases detected following PCR & 10 \\
\hline
\end{tabular}


No confirmed cases were reported from the NIHS FPA (other than from Punani Quarantine Centre) for more than two weeks from 8 April onwards. However, this successful containment was shortlasting as a new phase of case detection was observed from 24 April onwards among Navy soldiers returning from Welisara Navy Base. During the outbreak, there were a number of challenges in controlling the disease, however application of sound public health principles contributed to the suppression of the outbreak. It is most important to continue improving public awareness and to convince them of their roles and responsibilities in this global pandemic. With the experience at NIHS FPA, it can be concluded that application of public health principles through the existing public health network, while ensuring inter-sectoral action and community empowerment remains the key armament for disease suppression at grass root level.

\section{Author Declaration}

Acknowledgements: We acknowledge the director and field staff at NIHS who have supported in preparation of the manuscript in many ways.

Author contributions: All authors were involved in planning of the article and in literature search. VJ drafted the manuscript and all authors were involved in editing it. RF did the overall supervision. All authors approved the final manuscript.

\section{References}

1. WHO. COVID-19 pandemic remains public health emergency of international concern. World Health Organization, 2020. Available from:http:// www.euro.who.int/en/health-topics/healthemergencies/coronavirus-covid-19/news/news/ 2020/5/covid-19-pandemic-remains-publichealth-emergency-of-international-concern.

2. State Intelligence Service. Combating COVID-19 Sri Lankan approach 2020. Available from: http://chamber.1k/images /COVID19/pdf/ conceptpapergovt.pdf.

3. The College of Community Physicians of Sri
Lanka. Flattening the epidemic curve of COVID 19 in Sri Lanka: the public health response. Journal of the College of Community Physicians of Sri Lanka 2020; 26(1): 56-64. DOI: 10.4038/jccpsl.v $26 i 1.8311$.

4. NIHS. Annual Report of National Institute of Health Sciences, Sri Lanka 2011. Available from: http://nihs.gov.lk/nihs/images/docs /AReport/ AR2011.pdf.

5. ECDC. Contact tracing for COVID-19: current evidence, options for scale-up and an assessment of resources needed. European Centre for Disease Prevention and Control, 2020. Available from: https://www.ecdc. europa.eu/sites/default/files/ documents/COVID-19-Contract-tracing-scaleup.pdf.

6. Ministry of Health. Provisional Clinical Practice Guidelines on COVID-19 Suspected and Confirmed Patients. Ministry of Health, Sri Lanka, 2020. Available from: https:// www.epid.gov.lk/ web/images/pdf/Circulars/Corona_virus/covid19 \%20cpg\%20_\%20version\%204.pdf.

7. Epidemiology Unit. Guideline for the Home Quarantine /Quarantine in Non-health Care Settings. Ministry of Health \& Indigenous Medical Services, 2020. Available from: https://www.epid. gov.lk/web/images/pdf/Circulars/Corona_virus/gu idelines-ofhome-quarantine.pdf.

8. Hewage S, Wickramasinghe N, Jayakody S, Samaranayake D, Prathapan S, Arambepola C. Social distancing, and its impact on flattening the COVID-19 curve in Sri Lanka. Journal of the College of Community Physicians of Sri Lanka 2020; 26(1): 65-70. DOI: 10.4038/jccpsl.v26i1. 8314.

9. Ng K, Poon BH, Kiat Puar TH, Shan Quah JL, Loh WJ, Wong YJ, et al. COVID-19 and the risk to health care workers: a case report. Annals of Internal Medicine 2020; 172(11): 766-767. DOI:10.7326/L20-0175.

10. Kraaij-Dirkzwager MM, Schol LGC, SchuitmakerWarnaar TJ, Timen A, Van Steenbergen JE. Stakeholder Involvement in Outbreak Management. International Journal of Information Systems for Crisis Response and Management 2019; 11(2): 57-78. DOI: 10.4018/IJISCRAM. 2019070104 . 